\title{
Téoros
}

Revue de recherche en tourisme

\section{Tourisme et régions}

\section{Marc Laplante}

Volume 5, numéro 1, mars 1986

\section{Tourisme et régions}

URI : https://id.erudit.org/iderudit/1080582ar

DOI : https://doi.org/10.7202/1080582ar

Aller au sommaire du numéro

\section{Éditeur(s)}

Université du Québec à Montréal

\section{ISSN}

0712-8657 (imprimé)

1923-2705 (numérique)

Découvrir la revue

\section{Citer ce document}

Laplante, M. (1986). Tourisme et régions. Téoros, 5(1), 1-1.

https://doi.org/10.7202/1080582ar d'utilisation que vous pouvez consulter en ligne.

https://apropos.erudit.org/fr/usagers/politique-dutilisation/ 


\section{Présentation}

\section{Tourisme et régions}

"La culture régionale n"est pas contre la culture nationale mais contre la culture standard".

Gérard Delaplace ${ }^{[1]}$

Vivre en ce pays du Québec sans en connaître toutes ses régions, c'est en ignorer sa vraie mesure. D'autres viellles sociétés peuvent se rendre intéressantes aux visiteurs en leur révélant, par couches successives, les profondeurs de leurs temps superposés: ici, pour nous raconter, nous avons surtout nos espaces.

J'avais ces sentiments au moment de rejoindre chacun des auteurs de ce numéro pour les inviter à contribuer à une réflexion sur notre géométrie touristique ${ }^{(2)}$. Notre collegue André Barabé de l'Université du Québec à TroisRivierres, empéché par la maladie de poursuivre la coordination de la présente édition, $m$ 'a laissé un premier dossier avec une problématique que j'ai essayé de respecter essentiellement. // avait bien conscience des tiraillements actuels qui caractérisent nos timides efforts de régionalisation touristique: MRC, ATR et ministère du Tourisme sont aujourd'hui penchés sur leur table à dessin pour concevoir des plans d'aménagement, des contrats de développement, des études de localisation, etc. Plus de la moitié des MRC ont retenu le tourisme parmi leurs priorites! L'illusion tenace que /'industrie touristique est une grosse affaire au Québec sera bientôt schématisée, car= tographiee, érigée en plans, programmes et politiques.

Heureusement, certains textes du présent numéro viennent sonner /'alarme pour que cette frenesie se calme un peu. D'Abitibi-Témiscamingue, de l'Est du Québec, de l'Estrie, de Charlevoix, nous entendrons que la régionalisation ne peut être une panacée. Les régions sont des entités globales, sociales et culturelles autant - sinon plus - qu'économiques; pressées de produire des images de marque touristiques pour leurs brochures promotionnelles, leurs priorités de développement, leurs projets d'investissement, presque obligées de se montrer sur leurs plus beaux atours pour recevoir la manne des derniers publics, ne risquent-elles pas, en fin de compte, de n'édifier que des facades!

(1) Mourements dcologustes er reghonalisies ies causes du mgrand refus. Cri thre: le rogion, acut $197 \mathrm{a}_{\mathrm{a}}$ p. 59

(2) Reflexion amorcte par un précédent numéro de Téoros consacré à l'aménage ment touristique IVol. 2 , no 3. 19831
La táche est en fait gigantesque, pour les intervenants régionaux du tourisme, de depasser les intéréts particuliers et immédiats pour arriver à saisir leur essence régionale. Ressources naturelles, groupements humains, histoire sociale, institutions propres, interactions avec les autres régions et l'ensemble du pays: autant de facet * tes des éventuelles personnalités régionales qui ne s'improvisent pas et qui, surtout, ne peuvent être imposées par quelques pouvoirs politiques ou financiers. Vingt fois sur la table a dessin remettez votre plan! Nous ne raconterons jamais le Quebec à nos visiteurs sans leur révéler l'authentique vérité de chacune de nos régions.

Je proposerais, quant à moi, qu'on inscrive désormais sur tous les documents abordant le thème des régions touristiques /'heureuse formule de G. Delaplace que j'ai placée en tête de mon texte car, chacun en conviendra, la standardisation culturelle reste aujourd'hui le plus grand danger du développement touristique.

\section{Marc Laplante}

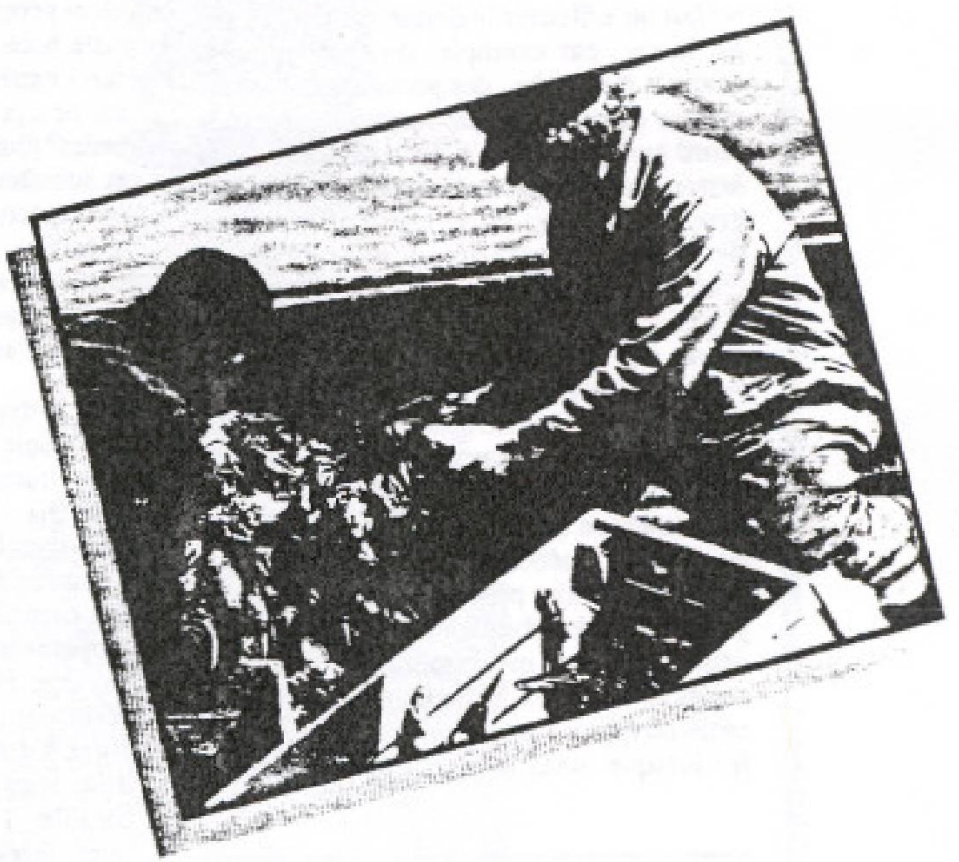

